\title{
Fabrication of Easy Separable and Reusable Adsorbent Composite based on MIL-125/MIL-53 Binary MOF/CNT/Alginate Microbeads for Aremoval of Tetracycline from Water Bodies
}

Ahmed M. Omer ( $\nabla$ amomar@srtacity.sci.eg )

City of Scientific Research and Technological Applications (SRTA-City)

Eman M. Abd El-Monaem

Alexandria University

Gehan M. El-Subruiti

Alexandria University

Mona M. Abd El-Latif

City of Scientific Research and Technological Applications (SRTA-City)

Abdelazeem S. Eltaweil

Alexandria University

\section{Research Article}

Keywords: Binary MOF, Alginate, Carbon nanotube, Tetracycline, Adsorption, Reusability

Posted Date: July 26th, 2021

DOI: https://doi.org/10.21203/rs.3.rs-729166/v1

License: (c) (1) This work is licensed under a Creative Commons Attribution 4.0 International License.

Read Full License 


\section{Fabrication of easy separable and reusable adsorbent composite based on MIL- 125/MIL-53 binary MOF/CNT/Alginate microbeads for adsorptive removal of tetracycline from water bodies}

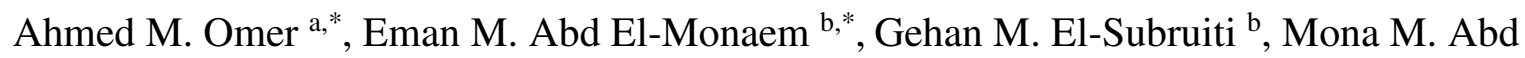
El-Latif ${ }^{c}$ and Abdelazeem S. Eltaweil ${ }^{\text {b,* }}$

${ }^{\text {a }}$ Polymer Materials Research Department, Advanced Technology and New Materials Research Institute (ATNMRI), City of Scientific Research and Technological Applications (SRTA-City), New Borg El-Arab City, P. O. Box: 21934, Alexandria, Egypt

${ }^{\mathrm{b}}$ Chemistry Department, Faculty of Science, Alexandria University, Alexandria, Egypt

${ }^{\mathrm{c}}$ Fabrication Technology Department, Advanced Technology and New Materials Research Institute (ATNMRI), City of Scientific Research and Technological Applications (SRTA-City), New Borg El-Arab City, P. O. Box: 21934, Alexandria, Egypt

*Correspondence: Ahmed M. Omer (A.M.O.) (amomar@srtacity.sci.eg), Abdelazeem S. Eltaweil (A.S.E.) (abdelazeemeltaweil@alexu.edu.eg)and Eman M. Abd El-Monaem (emanabdelmonaem5925@yahoo.com) Tel.: +20-3-4593414

\section{Abstract}

During the turbulent period of COVID-19, the medical staff is exerting great efforts to preserve humanity. However, the tons of pharmaceutical residues especially antibiotics that is being disposing daily into water bodies may be the seed to an even more ferocious pandemic. Thence, it is inevitable to find out effective strategies for removing these noxious pharmaceutical residues from water. We aimed in this investigation to fabricate easy separable composite microbeads for efficient adsorption of tetracycline (TC) drug. Herein, MIL-125/MIL-53 binary metal organic framework (MOF) was synthetized and incorporated with carbon nanotube (CNT) into alginate (Alg) microbeads to form MIL-125/MIL-53/CNT@Alg composite microbeads. Various tools including FTIR, XRD, SEM, BET, Zeta potential and XPS were applied to characterize the composite microbeads. The results revealed that the adsorption of TC was augmented with rising TC proportion up to $15 \mathrm{wt} \%$ in the 
microbeads matrix. In addition, the adsorption process followed the pseudo-secondorder and well-fitted to Freundlich and Langmuir models with a maximum adsorption capacity of $294.12 \mathrm{mg} / \mathrm{g}$ at $25{ }^{\circ} \mathrm{C}$, while the adsorption process was endothermic, randomness and spontaneous. Besides, reusability test signified that MIL-125/MIL53/CNT@Alg composite microbeads retained admirable adsorption properties for six consecutive cycles, emphasizing its potentiality for removing of pharmaceutical residues.

Keywords: Binary MOF; Alginate; Carbon nanotube; Tetracycline; Adsorption; Reusability.

\section{Introduction}

Presently, the scarcity of drinking water is the major problem that is sweeping the world, menacing humanity with annihilation ${ }^{1}$. During the cruel circumstances of COVID-19, one source of water pollution has reached its peak which is pharmaceutical contaminants. In this regard, antibiotics such as tetracyclines (TCs) have been recommended in new research that they may be able to treat COVID-19 infection through their anti-inflammatory and anti-apoptotic activities ${ }^{2-4}$. However, humans could not completely metabolize TCs and around $50-80 \%$ of the applied dosage is secreted via urine ${ }^{5}$. Thence, numerous developing techniques have been used for TCs removal from wastewater including; adsorption ${ }^{6}$, ultrasonic irradiation ${ }^{7}$, photocatalytic degradation ${ }^{8}$, membrane process ${ }^{9}$, and fenton oxidation ${ }^{10}$. Among the mentioned techniques; adsorption has been considered as the most favorable technique for the removal of TCs from wastewater owing to it is simple, economic, low-energy consumption, etc. ${ }^{11,12}$. 
Metal organic frameworks (MOFs) is a new brilliant class of crystalline materials that has increasingly drawn a vast consideration owing to its versatile applications 13,14. Notably, owing to the unique characteristics of MOFs such as water stability, ultrahigh porosity, easy functionalization, thermal stability and high surface area, MOFs have successfully been utilized for the adsorptive removal of heavy metals ${ }^{15}$, pharmaceutical contaminants ${ }^{16}$ and synthetic dyes ${ }^{17}$. One of iron-based MOFs that has been exhibiting notable adsorptive behavior is MIL-53 owing to its structure flexibility, stability in water and chemical stability ${ }^{18}$. Furthermore, MIL-125 is one more bright member in MIL-family that possesses promising photo-catalytic and adsorptive behavior due to its photo-reactivity, thermal and chemical stability, etc. ${ }^{19}$. Although, the individual features of MOFs, there is a huge obstacle to apply them in practical applications which is the difficulty of their recycling as well as their difficult separation from the adsorption mediums. Fabrication of the shaping MOFs like membrane, fiber and beads is considered an effective solution to get rid of MOFs drawback ${ }^{20,21}$. Sodium alginate (Alg); is a water-soluble anionic polysaccharide that is smoothly extracted from brown seaweed ${ }^{22}$. Alginate has acquired huge fame owing to its unique merits such as biodegradability, nontoxicity, strong gelation, biocompatibility, high chemical stability, chelating ability and possession of abundant function groups onto its surface (i.e. hydroxyl and carboxyl) ${ }^{23-26}$. Therefore, Alg has been considered a premium-supporting host of chemical and biological compounds in several potential applications including pharmaceutical, biomedical and especially in wastewater treatment owing to its ability to capture the cationic ions from the target contaminants whether heavy metals or dyes via ion-exchange mechanism ${ }^{22,27,28}$.

The remarkable features of carbon nanotubes (CNTs) including high mechanical strength, high surface area, low cost and its ability to form strong bonds with other 
molecules or atoms, make them promising candidates for the adsorptive removal of diverse pollutants from wastewater ${ }^{29}$. Moreover, multi-walled CNTs are higher accessible and lower cost than single-walled CNTs which render multi-walled CNTs more favorable for the potential applications than single-walled CNTs ${ }^{30}$.

Herein, we aimed to fabricate a novel binary MOF/ CNT composite embedded into Alg microbeads to facilitate the separation of MIL-125/MIL-53 binary MOF after the adsorption process as well as ameliorate its efficiency and reusability. The fabricated MIL-125/MIL-53/CNT@Alg composite microbeads were characterized by bountiful tools as well as their adsorption aptitude towards TC was assessed utilizing a batch adsorption technique. The kinetics, isotherms and thermodynamics were adequately studied. Furthermore, to prove the economic viability of the fabricated MIL-125/MIL53/CNT@Alg composite microbeads, recyclability test was investigated.

\section{Experimental part}

\subsection{Materials}

Ferric chloride hexahydrate $\left(\mathrm{FeCl}_{3} \cdot 6 \mathrm{H}_{2} \mathrm{O}\right)$ and carbon nanotubes (multi-walled type) were purchased from Alpha Chemika (India). Titanium isoproproxide (TBOT), sodium alginate (medium viscosity) and N,N dimethyl formamide (DMF) were obtained from Shanghai Chemical Reagent (China). Tetracycline and 1,4-benzene dicarboxylic acid (BDC) were bought from Loba Chemie Ltd (India). Ethanol, ammonium solution $\left(\mathrm{NH}_{4} \mathrm{OH}\right)$ and dimethyl sulfoxide (DMSO) were provided by Ninghai Jiahe (China).

\subsection{Synthesis of MIL-125/MIL-53 binary MOF}

MIL-125/MIL-53 binary MOF was fabricated as follows; exactly, $0.679 \mathrm{~g}$ $\mathrm{FeCl}_{3} .6 \mathrm{H}_{2} \mathrm{O}$ and $0.415 \mathrm{~g} \mathrm{BDC}$ were dissolved in $50 \mathrm{~mL}$ DMF and then the reaction 
mixture was kept under continuous stirring at $60{ }^{\circ} \mathrm{C}$ for $2 \mathrm{~h}$. In another container, $1.990 \mathrm{~g}$ BDC was dissolved in $50 \mathrm{~mL}$ DMF and then $2.7 \mathrm{~mL}$ TBOT was added drop by drop under vigorous stirring followed by stirring at $60{ }^{\circ} \mathrm{C}$ for $2 \mathrm{~h}$. Next, the two solutions were mixed, then transferred to $500 \mathrm{~mL}$ autoclave and heated at $140{ }^{\circ} \mathrm{C}$ for $20 \mathrm{~h}$. finally, the obtained powder was collected by centrifugation, washed and dried at $100{ }^{\circ} \mathrm{C}$ for $24 \mathrm{~h}$.

\subsection{Fabrication of MIL-125/MIL-53/CNT@Alg composite microbeads}

MIL-125/MIL-53/CNT@Alg composite beads were fabricated as follows; Alg was dissolved into $50 \mathrm{~mL}(5 \% \mathrm{wt} / \mathrm{v})$ dist. $\mathrm{H}_{2} \mathrm{O}$ under robust mechanical stirring until a clear jelly solution was formed. In another beaker, 5 g MIL-125/MIL-53 binary MOF and $\mathrm{CNT}(5,10,15$ and $20 \mathrm{wt} \%)$ were soaked into $50 \mathrm{~mL}$ dist. $\mathrm{H}_{2} \mathrm{O}$ and sonicated for $2 \mathrm{~h}$. Then after, the homogenous solution of MIL-125/MIL-53 binary MOF/CNT was added to Alg solution dropwise and stirred for $1 \mathrm{~h}$. MIL-125/MIL53 binary MOF/CNT/Alg solution was added by syringe into a pre-prepared gelling agent of $\mathrm{CaCl}_{2}(2 \% \mathrm{wt} / \mathrm{v})$ and kept the obtained microbeads under slow stirring for 1 h. Finally, MIL-125/MIL-53/CNT@Alg composite microbeads were collected, washed several times with distilled water and dried at room temperature.

Figure 1 represents a schematic representation for the fabrication of MIL-125/MIL53/CNT@Alg composite beads 


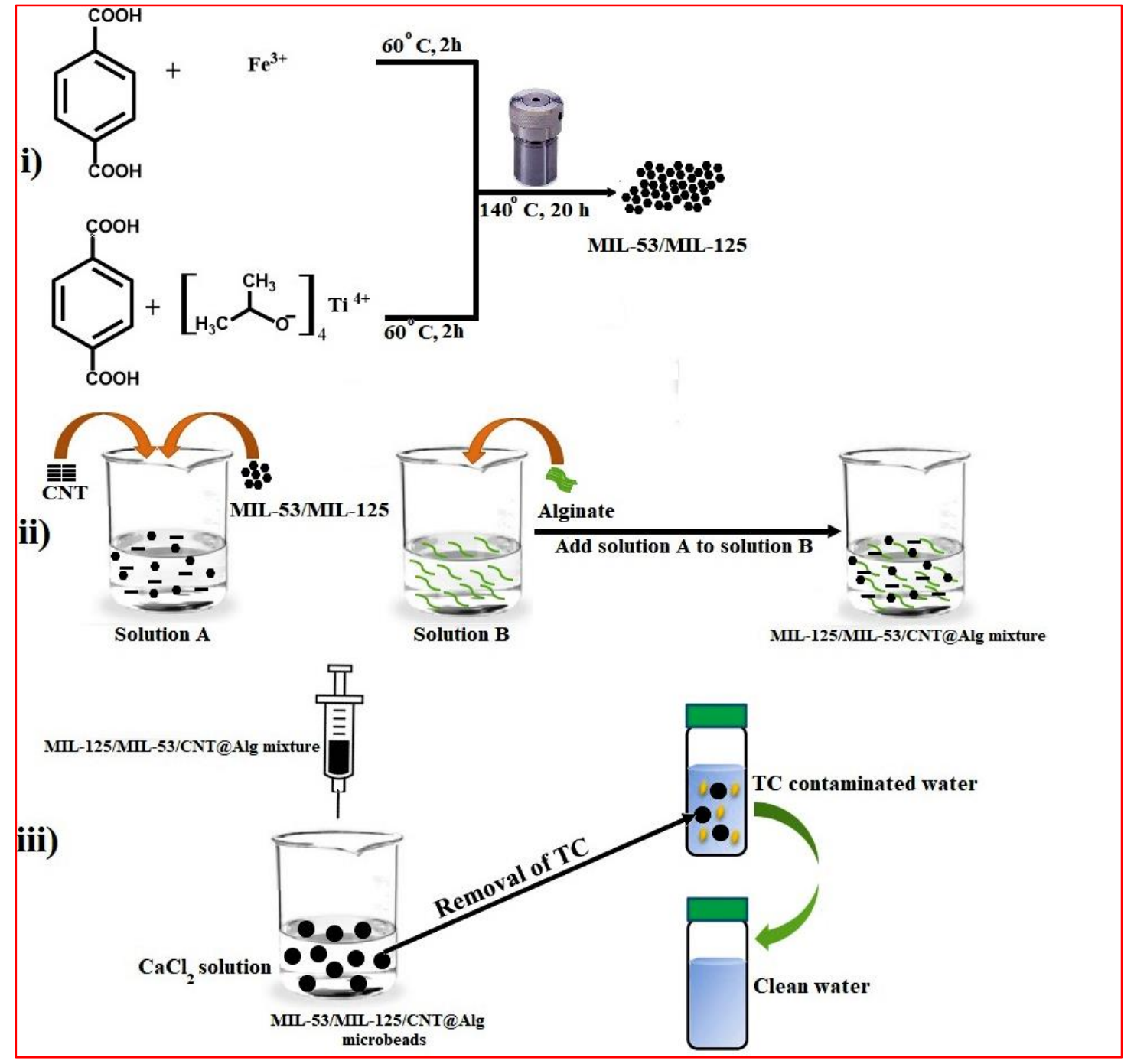

Figure 1. Schematic representation for the fabrication of MIL-125/MIL53/CNT@Alg composite microbeads and their adsorption process for TC removal.

\subsection{Characterization}

MIL-125/MIL-53/CNT@Alg composite microbeads were thoroughly characterized by; Fourier Transform Infrared spectra (FTIR- Tensor II, Bruker) to investigate the chemical composition of the synthesized microbeads. Furthermore, X-ray diffractometer (XRD- MAC Science M03XHF) was used to distinguish the crystal phase. The morphology was defined by a Scanning Electron Microscope (SEMHitachi-S4800), while the thermal stability of the developed composite microbeads 
was identified by Thermogravimetric Analysis (TGA- Shimadzu-50). Besides, X-ray photoelectron spectroscopy (XPS- Thermo scientific-ESCALAB-250Xi VG) was employed to clarify the elemental compositions of the adsorbent. The specific surface area of composite microbeads was measured by Bruner-Emmett-Teller method (BETBeckman coulter SA3100), while their surface charges were determined by Zeta potential (ZP- Malvern-UK).

\subsection{Batch experiment}

The key parameters that affect the efficiency of the TC adsorption onto MIL125/MIL-53/CNT@Alg composite microbeads were studied precisely using batch mode. During the whole adsorption experiments TC solution was wrapped with aluminum foil to prevent photodegradation of TC. For specifying the optimum $\mathrm{pH}, 20$ $\mathrm{mg}$ of dry adsorbent microbeads were soaked into $25 \mathrm{~mL}$ TC solution at $\mathrm{pH}$ range from 2 to 10 and stirred for 60 min under agitation rate $150 \mathrm{rpm}$. While, for investigating the effect of adsorbent dose, various doses of MIL-125/MIL53/CNT@Alg composite microbeads at range from 10 to $80 \mathrm{mg}$ were added to TC solution at the identified optimum pH. Furthermore, the TC adsorption isotherm was studied at an initial concentration range from 50 to $300 \mathrm{mg} / \mathrm{L}$. Besides, the thermodynamic study was executed at a temperature range from 25 to $55^{\circ} \mathrm{C}$. At a set time, the un-adsorbed TC concentration was evaluated by withdrawing a sample and measured using spectrophotometry at $354 \mathrm{~nm}$. The removal (\%) and adsorption capacity (q) were computed by the following equations;

$$
\begin{aligned}
& \mathrm{R} \%=\frac{\mathrm{C}_{0}-\mathrm{C}_{\mathrm{t}}}{\mathrm{C}_{0}} \times 100 \\
& \mathrm{q}_{\mathrm{e}}=\frac{\left(\mathrm{C}_{0}-\mathrm{C}_{\mathrm{t}}\right) \times \mathrm{V}}{\mathrm{w}}
\end{aligned}
$$


Where, $\mathrm{C}_{0}$ and $\mathrm{C}_{\mathrm{t}}$ symbolize the $\mathrm{TC}$ initial concentration and its concentration at certain time, respectively. While, $\mathrm{V}$ and $\mathrm{w}$ symbolize the TC solution volume and the weight of MIL-125/MIL-53/CNT@Alg composite microbeads, respectively.

\subsection{Reusability study}

Undoubtedly, regeneration behavior is one of the main criteria for choosing an adsorbent. Consequently, the reusability study was implemented for five successive cycles as follows; after each adsorption process, MIL-125/MIL-53/CNT@Alg composite microbeads were collected and soaked in $(50 \mathrm{~mL}, 0.01 \mathrm{M}) \mathrm{NaOH}$ under constant stirring. After 1 h, MIL-125/MIL-53/CNT@Alg composite microbeads were collected and examined in the next cycle.

\section{Results and Discussion}

\subsection{Characterization of MIL-125/MIL-53/CNT@Alg composite beads}

\subsubsection{XRD}

Figure 2 depicts XRD patterns of MIL-125/MIL-53 binary MOF, CNT and MIL125/MIL-53/CNT@Alg composite microbeads. Figure 2A implies the successful fabrication of MIL-125/MIL-53 binary MOF at which the prime peaks of both MIL125 and MIL-53 obviously appeared ${ }^{18,31}$. Moreover, XRD pattern of CNT (Figure 2B) illustrates the distinguishing peaks of CNT at $2 \theta=25.81^{\circ}$ and 43.28 which correspond to 100 and 101 planes, respectively ${ }^{32}$. Besides, XRD pattern of MIL125/MIL-53/CNT@Alg (Figure 2C) infers the successful combination of MIL125/MIL-53, CNT and Alg since the distinctive peaks of the components emerged with decreasing in the crystallinity of the peaks which might be due to the amorphous phase of Alg. 


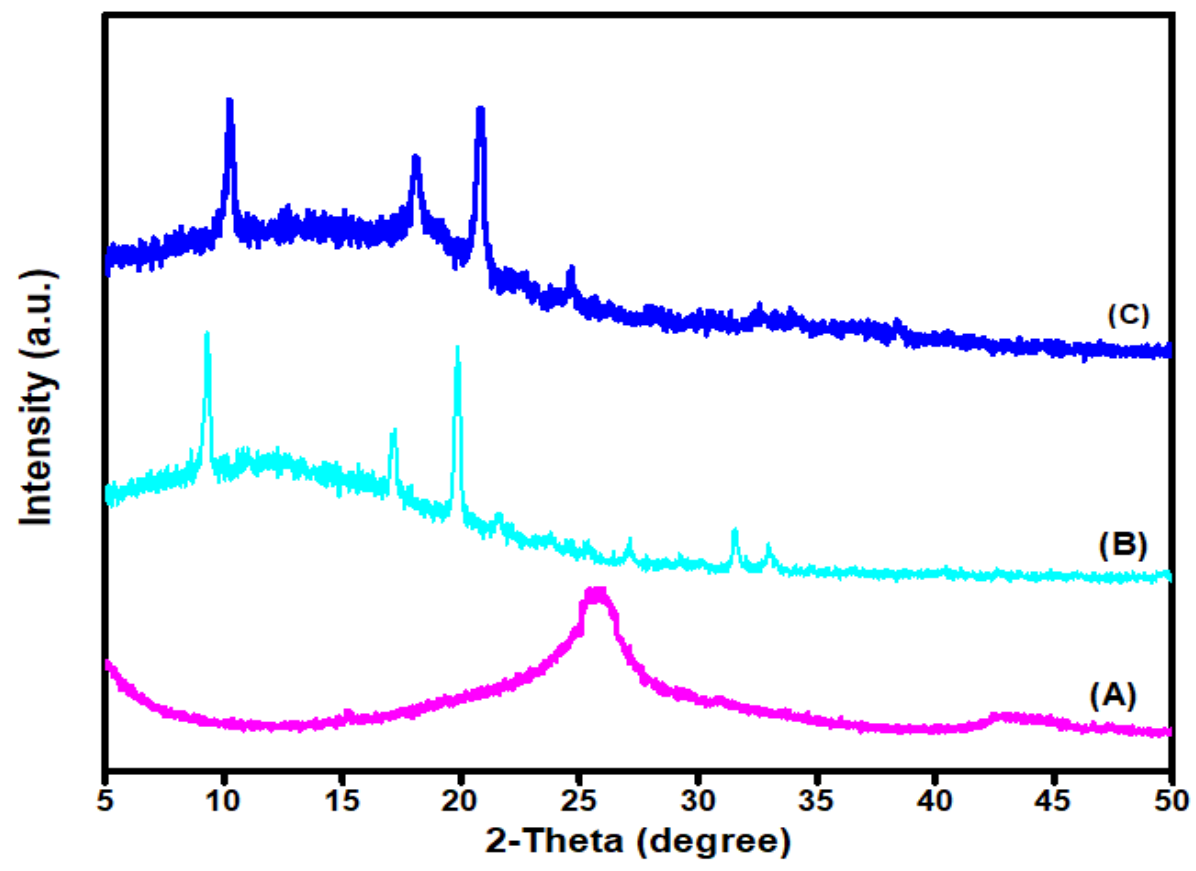

Figure 2. XRD patterns of (A) MIL-125/MIL-53 binary MOF, (B) CNT and (C) MIL-125/MIL-53/CNT@Alg composite microbeads

\subsubsection{FTIR}

In order to thoroughly investigate the functional groups of the fabricated MIL125/MIL-53/CNT@Alg composite microbeads and the pristine components, FTIR analysis was executed and the resulted are presented in Figure 3. FTIR spectrum of MIL-125/MIL-53 binary MOF (Figure 3A) depicts the main distinctive peaks of both MIL-125 and MIL-53. The bands at around 650 and $735 \mathrm{~cm}^{-1}$ could be attributed to Fe-O and Ti-O bending vibrations ${ }^{33,34}$. Whereas, the bands at 1101 and $1291 \mathrm{~cm}^{-1}$ are assigned to $\mathrm{C}-\mathrm{H}$ and $\mathrm{C}-\mathrm{O}$, respectively ${ }^{35}$. Besides, the two bands at 1385 and 1581 $\mathrm{cm}^{-1}$ are ascribed to the vibration of the carboxyl group of BDC that coordinates to the metal centers (i.e. Ti and Fe) ${ }^{31}$. Figure 3B depicts the distinguishing bands of CNT at 1650,2330 and $2675 \mathrm{~cm}^{-1}$ which are attributed to $\mathrm{C}=\mathrm{C}$, the formed $\mathrm{H}$-bond and $\mathrm{C}$ $\mathrm{H}^{36,37}$. In the $\mathrm{Alg}$ spectrum (Figure 3C), the band at $799 \mathrm{~cm}^{-1}$ is related to $\mathrm{C}-\mathrm{H}$ vibration of pyranose, while the band at around $2916 \mathrm{~cm}^{-1}$ is ascribed to $\mathrm{C}-\mathrm{H}$ stretching vibration. Besides, the band at $1019 \mathrm{~cm}^{-1}$ is ascribed to $\mathrm{C}-\mathrm{O}$ stretching and 
the band around $3250 \mathrm{~cm}^{-1}$ belongs to $\mathrm{OH}$ stretching vibration ${ }^{38,39}$. In addition, the belonging peaks to asymmetric and symmetric $\mathrm{COO}^{-}$group emerged at 1401 and $1592 \mathrm{~cm}^{-1}$, respectively. Besides, the observed band at $2330 \mathrm{~cm}^{-1}$ is assigned to $\mathrm{CO}_{2}$ group ${ }^{40}$. Figure 3D clarifies the main characteristic bands of the pristine components, suggesting the successful combination between them.

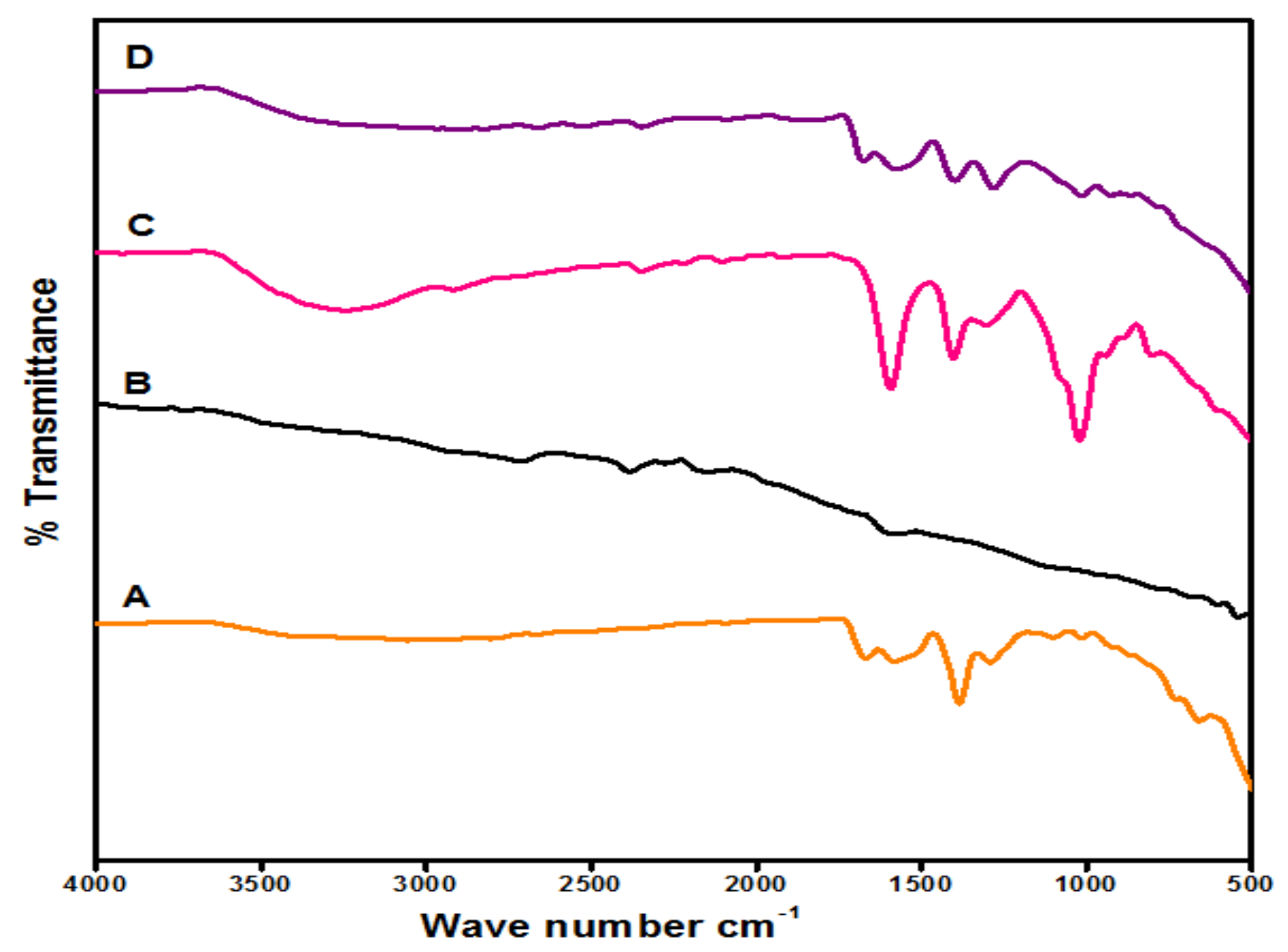

Figure 3. FTIR spectra of (A) MIL-125/MIL-53 binary MOF, (B) CNT, (C) alginate and (D) MIL-125/MIL-53/CNT@ Alg composite microbeads

\subsubsection{SEM}

Figure 4A points out aggregated quasi-spherical particles of MIL-125/MIL53/CNT@Alg. Whereas, Figure 4B depicts the typical cylindrical shape of CNT in nano size. Furthermore, SEM image of pristine Alg microbeads (Figure 4C) reveals that the beads have an elongated shape. In addition, the closer image of the surface of Alg microbeads (Figure 4D) clarifies a rugged surface with large crevices, reflecting the low mechanical strength that causes the collapse of Alg layers during dehydration. 
On the other hand, (Figure 4E) shows a perfectly spherical shape of the fabricated MIL-125/MIL-53/CNT@Alg composite microbeads. Furthermore, the surface of the microbeads (Figure 4F) has no fissures, assorting an ameliorated mechanical strength of MIL-125/MIL-53/CNT@Alg composite microbeads compared to pristine Alg microbeads.
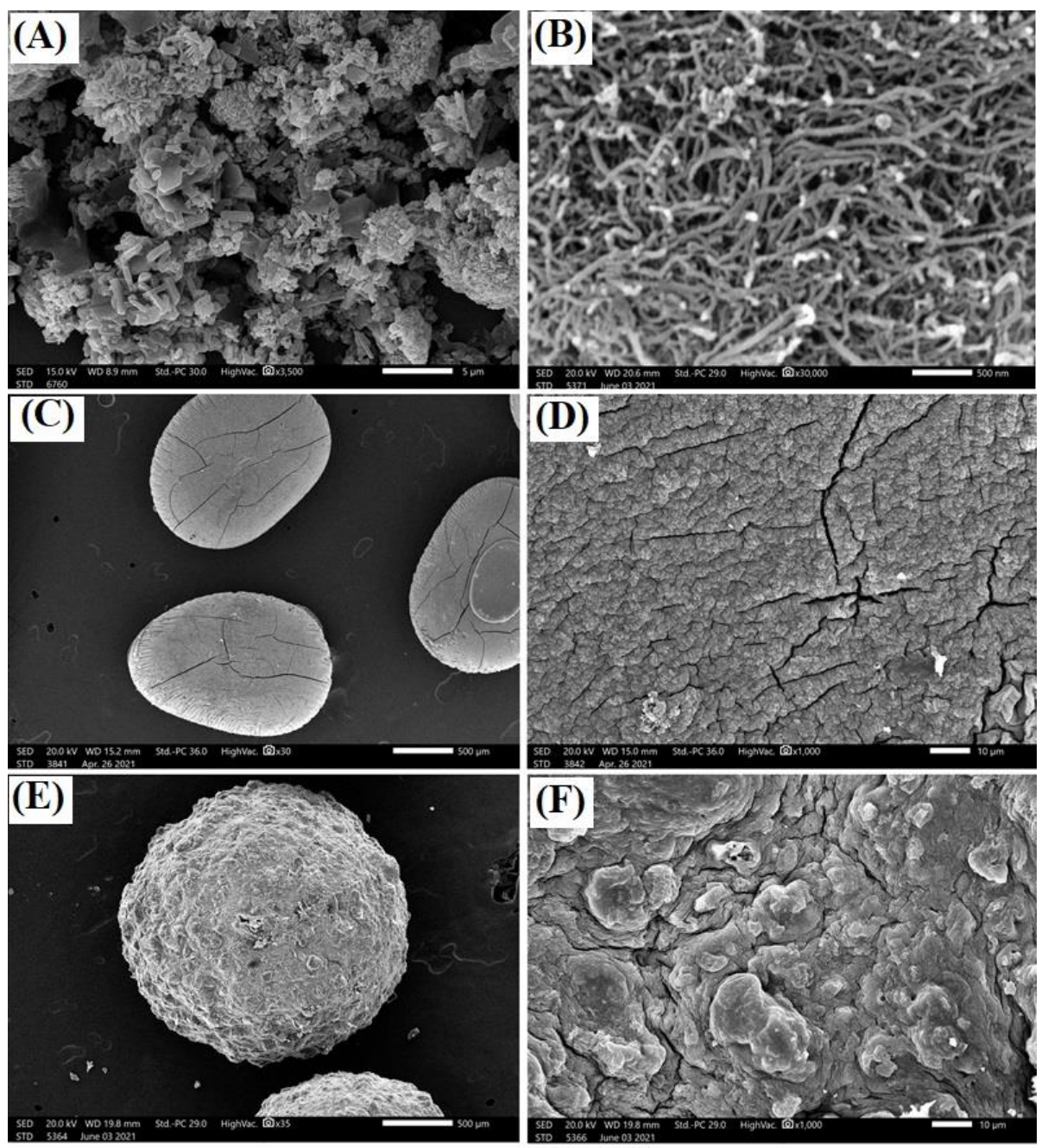

Figure 4. SEM images of (A) MIL-125/MIL-53 binary MOF, (B) CNT (C, D) alginate microbeads and (E, F) MIL-125/MIL-53/CNT@Alg composite microbeads.

\subsubsection{XPS}

XPS was utilized for an in-depth inspection of the elemental composition of MIL125/MIL-53/CNT@Alg composite microbeads and assuring from the successful 
combination of the fabricated matrix. It is apparent from the XPS survey (Figure 5A) that MIL-125/MIL-53/CNT@Alg consists of four main elements; C1s, O1s, Fe2p and Ti2p. The C1s-spectrum (Figure 5B) points out peaks at 284.54, 285.54 and 289.14 $\mathrm{eV}$ which are ascribed to the carbon-containing groups in MIL-125/MIL53/CNT@Alg C-C, C-O and O=C-O/O=C, respectively ${ }^{41,42}$. Moreover, the O1sspectrum (Figure 5C) obviously clarifies the belonging peak to $\mathrm{M}-\mathrm{O}$ (i.e. $\mathrm{M}$; $\mathrm{Ti}$ or $\mathrm{Fe}$ ) at BE of $532.14 \mathrm{eV}$, proving the formation of both MIL-125 and MIL-53. Besides, the appearance of peaks at 530.14 and $533.54 \mathrm{eV}$ are related to $\mathrm{C}-\mathrm{O}$ and $\mathrm{O}=\mathrm{C}-\mathrm{O}$, respectively ${ }^{43,44}$. In addition, $\mathrm{Fe} 2 \mathrm{p}$-spectrum (Figure 5D) infers the existence of $\mathrm{Fe}^{2+}$ and $\mathrm{Fe}^{3+}$ at which the related peaks to $\mathrm{Fe}^{2+}$ revealed at 710.66 and $756.33 \mathrm{eV}$. While pertinent peaks to $\mathrm{Fe}^{3+}$ at 712.88 and $729.33 \mathrm{eV}^{45}$. Besides, the Ti2p-spectrum (Figure 5E) shows the relevant peaks of $\mathrm{Ti}^{4+}$ (titanium dioxide) at $\mathrm{BE}$ of 458.74 and $464.67 \mathrm{eV}$, as well as the distinctive peaks to $\mathrm{Ti}^{3+}$ (titanium suboxide) at $\mathrm{BE}$ of 450.68 $\mathrm{eV}^{46}$. 

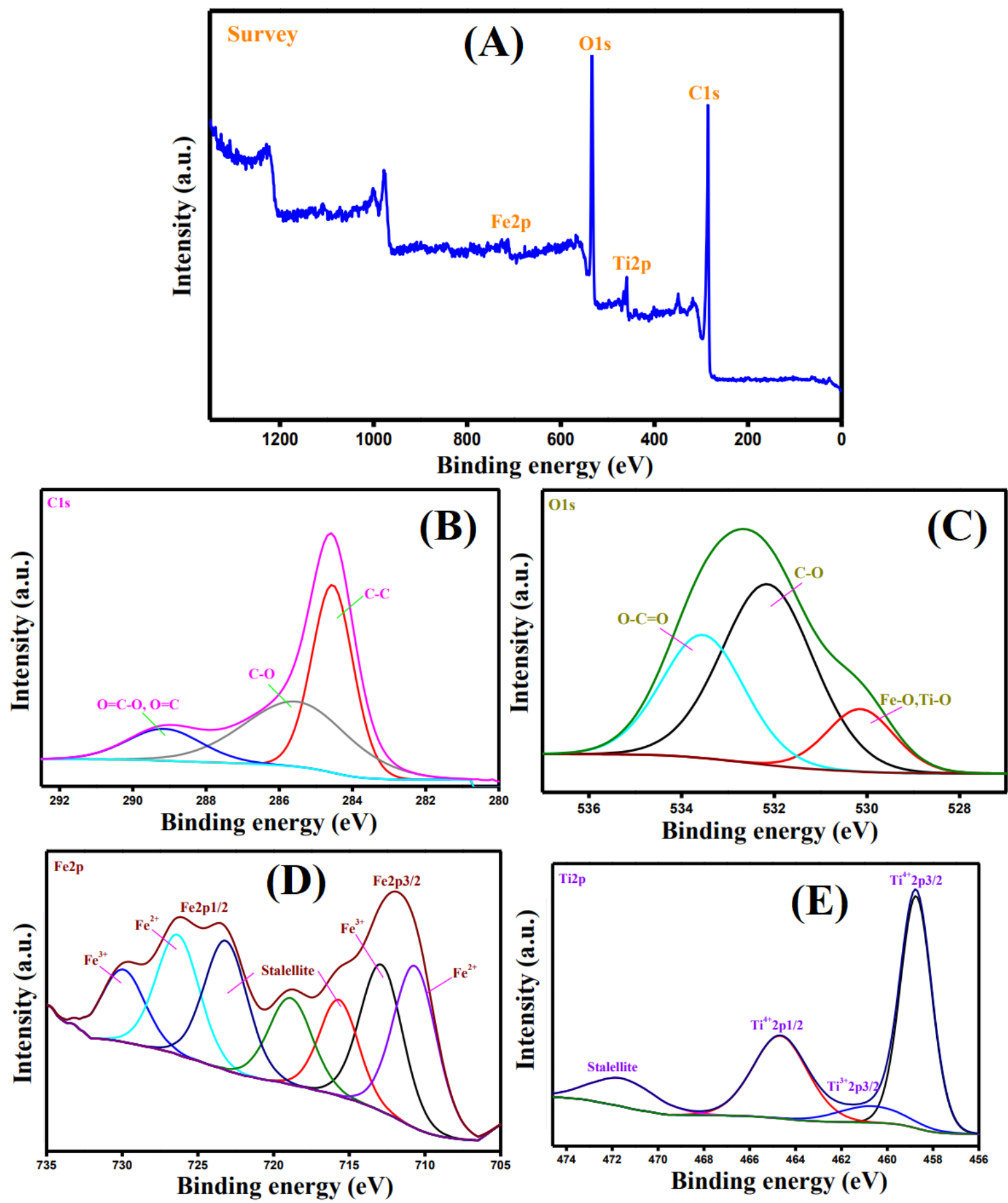

Figure 5. XPS spectra (A) wide scan, (B) C1s, (C) O1s, (D) Fe2p, and (E) Ti2p of MIL-125/MIL-53/CNT@Alg composite microbeads.

\subsubsection{BET}

$\mathrm{N}_{2}$ adsorption/desorption isotherm of MIL-125/MIL-53/CNT@Alg is presented in

Figure 6 along with pore size distribution (inset). The MIL-125/MIL-53/CNT@Alg 
composite showed type IV isotherm with $\mathrm{H}_{4}$ hysteresis loop demonstrating a mesoporous structure of MIL-125/MIL-53/CNT@Alg microbeads composite. The S $\mathrm{m}^{2} / \mathrm{g}$ with pore volume of $0.0131 \mathrm{~cm}^{3} / \mathrm{g}$.

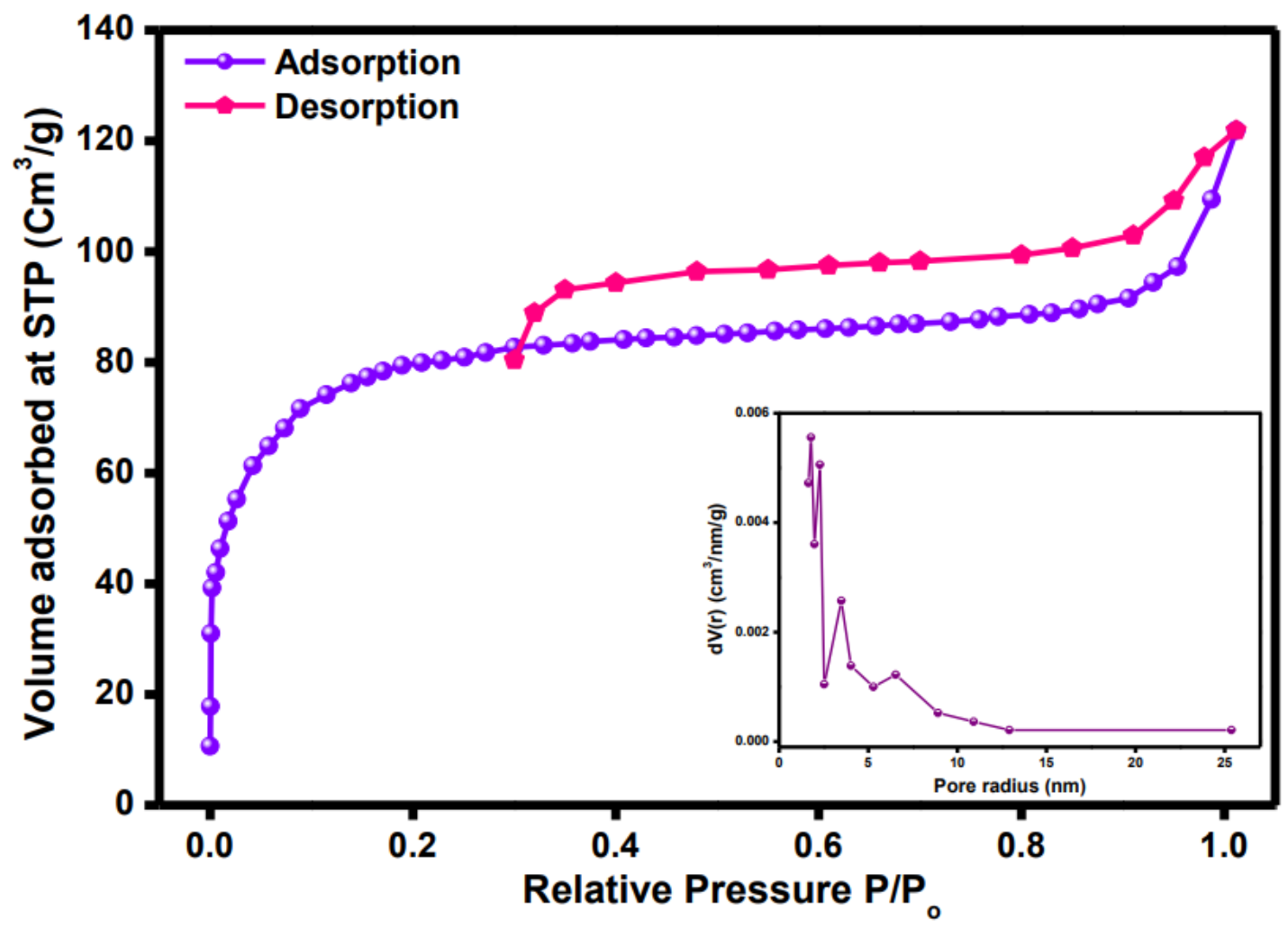

Figure 6. $\mathrm{N}_{2}$ adsorption/desorption isotherm and pore size distribution (inset) of MIL125/MIL-53/CNT@Alg composite microbeads

\subsection{Effect of the adsorption condition.}

\subsubsection{Effect of CNT proportion}

Figure 7A demonstrates the effect of CNT proportion on the adsorption capacity and the removal efficiency of TC onto MIL-125/MIL-53/CNT@Alg composite microbeads. It is apparent that the presence of CNT in the fabricated microbeads has vast leverage since it boosts the adsorptive performance of MIL-125/MIL-53 binary MOF@Alg composite microbeads towards TC. Furthermore, it was found that the 
increase in CNT proportion from 5 to $15 \mathrm{wt} \%$ increases the removal (\%) from 44.20 to $65.10 \%$ and the adsorption capacity from 29.76 to $42.02 \mathrm{mg} / \mathrm{g}$. While the excessive CNT proportion over $15 \mathrm{wt} \%$ causes a slight decrease in the removal (\%) from 65.10 to $61.29 \%$ and the adsorption capacity from 42.02 to $39.76 \mathrm{mg} / \mathrm{g}$ which may be due to the pore blocking effect, resulting from the excessive CNT proportion in the microbeads matrix ${ }^{34}$.

\subsubsection{Effect of $\mathrm{pH}$}

The pH influence on the adsorption behavior of MIL-125/MIL-53/CNT@Alg composite microbeads towards $\mathrm{TC}$ was scrutinized at a $\mathrm{pH}$ range from 2 to 10 . In fact, TC molecule exists in multi forms, depending on the solution $\mathrm{pH}$ at which $\mathrm{TC}$ is cationic $\left(\mathrm{TCH}_{3}{ }^{+}\right)$at $\mathrm{pH}<3.3$, zwitterionic $\left(\mathrm{TCH}_{2}{ }^{0}\right)$ at $3.3<\mathrm{pH}<7.7$ and anionic $\left(\mathrm{TCH}^{-}\right.$or $\left.\mathrm{TC}^{2-}\right)$ at $\mathrm{pH}>7.7^{12}$. Figure $7 \mathbf{B}$ elucidates an evolution in the adsorption capacity and the removal (\%) from $37.69 \mathrm{mg} / \mathrm{g}$ and $56.25 \%$ to $42.68 \mathrm{mg} / \mathrm{g}$ and 64.70 $\%$, respectively, with the rising in $\mathrm{pH}$ from 2 to 6 . Nevertheless, at this $\mathrm{pH}$ range, the positive charges on the TC molecule diminish and the negative charges on the surface of the composite microbeads increase from -12.5 to $-23.3 \mathrm{mV}$ based on the $\mathrm{ZP}$ result (Figure 7C), inferring that the adsorption of TC onto MIL-125/MIL-53/CNT@Alg composite microbeads is not dominated by electrostatic interaction. Also, this result is confirmed by the slight diminution in the adsorption capacity and the removal (\%) beyond pH 6 from $42.68 \mathrm{mg} / \mathrm{g}$ and $64.70 \%$ to $39.23 \mathrm{mg} / \mathrm{g}$ and $58.63 \%$, respectively. However, the electrostatic repulsion between TC and MIL-125/MIL-53/CNT@Alg composite microbeads at which TC molecules dwell at this $\mathrm{pH}$ region as anionic and the microbeads surface significantly charged with negative charge reach $-30.1 \mathrm{mV}$ at pH 10. Accordingly, it was deduced that the adsorption of TC onto MIL-125/MIL53/CNT@Alg composite microbeads is not controlled by electrostatic interaction and 
there is another predominant interaction such as H-bond, hydrophobic interaction, and $\pi-\pi$ interaction. This result is consistent with the previous studies by Zhang, Xiong, Gao, and Alatalo $5,47-49$
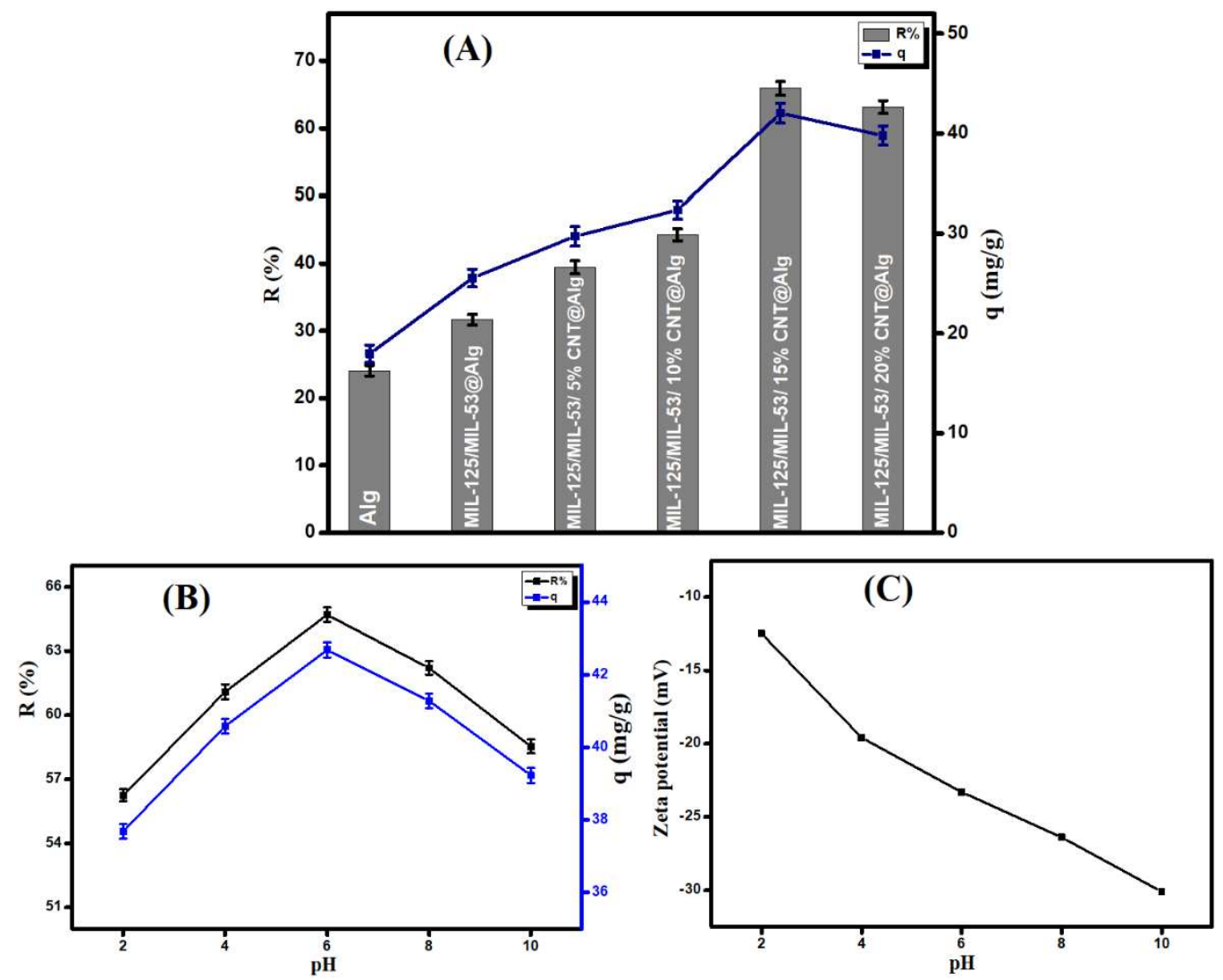

Figure 7. (A) Effect of CNT proportion and (B) Effect of pH, Effect of dosage on the removal efficacy and adsorption capacity of MIL-125/MIL-53/CNT@Alg composite microbeads and (C) zeta potential versus $\mathrm{pH}$ for MIL-125/MIL53/CNT@Alg composite microbeads.

\subsubsection{Effect of adsorbent dose}

Figure 8A points out the impact of the increase in the dose of MIL-125/MIL53/CNT@Alg composite microbeads on the removal (\%) and adsorption capacity of TC. As expected, the increment in the adsorbent dose from 0.01 to $0.08 \mathrm{~g}$ results in an increasing in the removal (\%) from 43.08 to $86.33 \%$ and a dropping in the adsorption capacity from 58.02 to $13.62 \mathrm{mg} / \mathrm{g}$. This behavior may be interpreted by the increment in the adsorbent dose leads to an increase in the provided active sites that renders the 
removal (\%) goes up. Contrariwise, the adsorption capacity dwindles due to the particles aggregation ${ }^{20}$.

\subsubsection{Effect of initial TC concentration}

Figure 8B demonstrates an increase in the adsorption capacity from 61.52 to $258.10 \mathrm{mg} / \mathrm{g}$ with the increase in the TC initial concentration from 50 to $300 \mathrm{mg} / \mathrm{L}$ which most likely due to the increase in the driving force of TC molecules towards MIL-125/MIL-53/CNT@Alg composite microbeads. On the contrary, the increase in the TC initial concentration decreases the removal (\%) from 98.19 to $65.08 \%$ (Figure 8C) which may be due to the insufficient active sites on the surface of the microbeads for adsorbing a high concentration of TC.
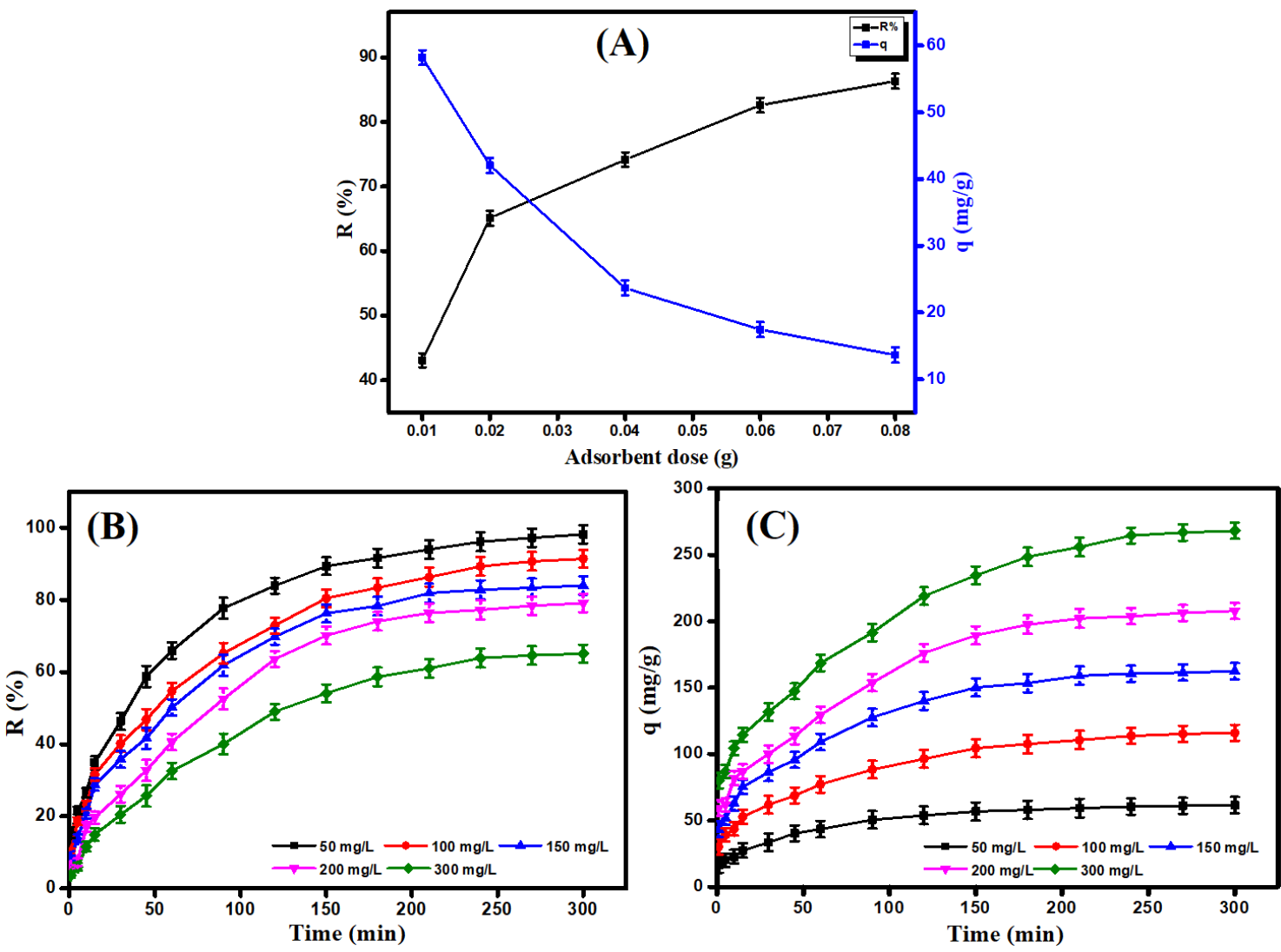

Figure 8. (A) Effect of adsorbent dose, $(\mathbf{B}, \mathbf{C})$ effect of initial concentration of the removal efficiency and adsorption capacity of TC onto MIL-125/MIL-53/CNT@Alg composite microbeads. 


\subsection{Isotherm study}

For interpreting the nature of interaction between TC and MIL-125/MIL53/CNT@Alg composite micrbeads, the experimental data were comprehensively analyzed by; Langmuir, Freundlich, Temkin and Dubinin-Radushkevich (D-R) isotherm models (Figure 9). The linear form of These models are expressed as follows ${ }^{50,51}$;

Langmuir equation: $\frac{\mathrm{C}_{\mathrm{e}}}{\mathrm{q}_{\mathrm{e}}}=\frac{1}{\mathrm{~K}_{\mathrm{L}} \mathrm{q}_{\mathrm{m}}}+\frac{\mathrm{C}_{\mathrm{e}}}{\mathrm{q}_{\mathrm{m}}}$

Freundlich equation: $\log \mathrm{q}_{\mathrm{e}}=\log \mathrm{K}_{\mathrm{F}}+\frac{1}{\mathrm{n}} \log \mathrm{C}_{\mathrm{e}}$

Temkin equation: $\mathrm{q}_{\mathrm{e}}=\mathrm{B} \ln \mathrm{A}+\mathrm{B} \ln \mathrm{C}_{\mathrm{e}}$

D-R equation: $\operatorname{Ln} \mathrm{q}_{\mathrm{e}}=\operatorname{Ln} \mathrm{q}_{\mathrm{s}}-\mathrm{K}_{\mathrm{ad}} \varepsilon^{2}$

Where, $\mathrm{q}_{\mathrm{e}}$ and $\mathrm{q}_{\mathrm{m}}$ the equilibrium adsorption capacity and the monolayer adsorption capacity, respectively. $\mathrm{C}_{\mathrm{e}}$ is the residual concentraion of $\mathrm{TC}$ at equilibrium and $\mathrm{K}_{\mathrm{L}}$ is Langmuir constant. $\mathrm{K}_{\mathrm{F}}$ and $\mathrm{n}$ are Freundlich constants. $\mathrm{B}=\frac{\mathrm{RT}}{\mathrm{b}}$, b is Temkin constant related to heat of adsorption and $\mathrm{A}$ is the equilibrium binding constant. $\mathrm{T}$ is the absolute temperature and $\mathrm{R}$ is the gas constant $(8.314 \mathrm{~J} / \mathrm{mol} \cdot \mathrm{k}) . \varepsilon=\mathrm{RT} \mathrm{Ln}(1+$ $\left.\frac{1}{C_{e}}\right)$ is the Polanyi potential. $K_{a d}$ is a constant related to mean free energy of adsorption per mole of adsorbate and $\mathrm{q}_{\mathrm{s}}$ is the saturation adsorption capacity. 

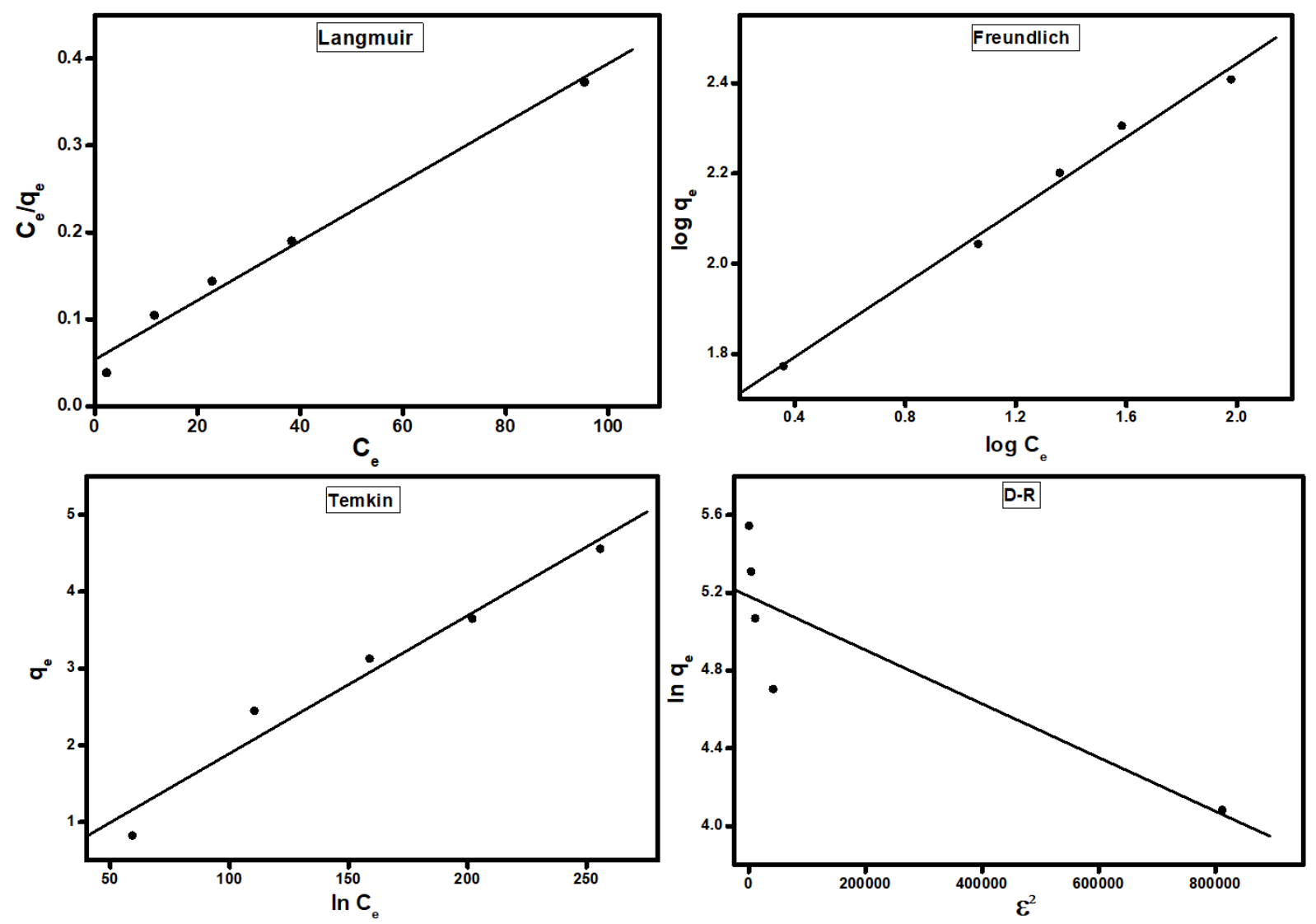

Figure 9. Isotherms plots for the TC adsorption onto MIL-125/MIL-53/CNT@ Alg composite microbeads; (A) Langmiur, (B) Freundlich, (C) Temkin and (E) D-R.

According to the $\mathrm{R}^{2}$ values (Table 1), the adsorption of TC onto MIL-125/MIL53/CNT@Alg composite microbeads fits Freundlich (0.995) and Langmuir (0.993) models, suggesting a monolayer and multilayer adsorption of TC. Furthermore, it was estimated from Langmuir that the maximum adsorption capacity is $294.12 \mathrm{mg} / \mathrm{g}$. Interestingly, $\mathrm{n}$ value proves the favorability of the adsorption of TC onto MIL125/MIL-53/CNT@Alg composite microbeads where $n>1$, as well as the $\mathrm{R}_{\mathrm{L}}$ values that fall in the range between $0-1$, is one more proof to confirm the favorability of the studied adsorption process. Besides, the calculated $\mathrm{E}$ value that less than 8 , confirming that the adsorption of TC onto MIL-125/MIL-binary MOF/CNT@Alg composite microbeads is physicosorption. 
Table 1. The parameters derived from isotherm models for the adsorption of TC onto MIL-125/MIL-53binary MOF/CNT@Alg composite microbeads

\begin{tabular}{|c|c|c|}
\hline Isotherm model & Parameter & Value \\
\hline & $\mathrm{q}_{\mathrm{m}}(\mathrm{mg} / \mathrm{g})$ & 294.12 \\
\hline \multirow[t]{3}{*}{ Langmuir } & $\mathrm{b}(\mathrm{L} / \mathrm{mg})$ & 0.063 \\
\hline & $\mathrm{R}^{2}$ & 0.993 \\
\hline & $\mathrm{n}$ & 2.265 \\
\hline \multirow[t]{3}{*}{ Freundlich } & $\mathrm{k}_{\mathrm{F}}(\mathrm{L} / \mathrm{mg})$ & 42.806 \\
\hline & $\mathrm{R}^{2}$ & 0.995 \\
\hline & $\mathrm{A}(\mathrm{L} / \mathrm{g})$ & 1.015 \\
\hline \multirow[t]{4}{*}{$\underline{\text { Temkin }}$} & $\mathrm{B}(\mathrm{J} / \mathrm{mol})$ & 53.583 \\
\hline & $\mathrm{b}(\mathrm{KJ} / \mathrm{mol})$ & 46.238 \\
\hline & $\mathrm{R}^{2}$ & 0.981 \\
\hline & $\mathrm{q}_{\mathrm{s}}$ & 178.11 \\
\hline \multirow{2}{*}{$\underline{\mathbf{D}-\mathbf{R}}$} & $\mathrm{K}_{\mathrm{ad}}\left(\mathrm{mol}^{2} / \mathrm{K}^{2} \mathbf{J}^{2}\right)$ & $1 \times 10^{-6}$ \\
\hline & $\mathrm{R}^{2}$ & 0.863 \\
\hline
\end{tabular}

\subsection{Kinetic study}

To deduce the adsorption mechanism of TC onto binary MIL-125/MIL-53 MOF/CNT@Alg composite microbeads, the experimental data were thoroughly modeled by pseudo-first-order, pseudo-second-order and Elovich model (Figure 10AC). Equations 7-10 symbolize the linear forms of these kinetic models ${ }^{50}$.

$$
\begin{aligned}
& \text { pseudo-first-order; } \ln \left(\mathrm{q}_{\mathrm{e}}-\mathrm{q}_{\mathrm{t}}\right)=\ln \mathrm{q}_{\mathrm{e}}-\mathrm{k}_{1}(\mathrm{t}) \\
& \text { pseudo-second- order; } \mathrm{t} / \mathrm{q}_{\mathrm{t}}=1 / \mathrm{k}_{2} \mathrm{q}_{\mathrm{e}}^{2}+1 / \mathrm{q}_{\mathrm{e}}(\mathrm{t}) \\
& \text { Elovich model; } \mathrm{q}_{\mathrm{t}}=\frac{1}{\beta} \ln (\alpha \beta)+\frac{1}{\beta} \ln (\mathrm{t})
\end{aligned}
$$


Where, $\mathrm{q}_{\mathrm{e}}$ represents the amount of TC that adsorbs onto MIL-125/MIL53/CNT@Alg composite microbeads at equilibrium, while $\mathrm{q}_{\mathrm{t}}$ expresses the amount of TC adsorption at time $\mathrm{t} . \mathrm{k}_{1}$ is the rate constant of pseudo-first-order and $\mathrm{k}_{2}$ is the rate constant pseudo-second- order. $\alpha$ and $\beta$ are Elovich coefficients that represent the initial adsorption rate and the desorption coefficient, respectively, also relate to the extent of surface coverage and activation energy for chemisorption.

To find out the suitable kinetic model that fits the experimental data there are two main criteria; $\mathrm{R}^{2}$ of the suitable kinetic model should be higher than $\mathrm{R}^{2}$ of the other applied models as well as the presence of an analogy between $\mathrm{q}_{\exp }$ and $\mathrm{q}_{\mathrm{cal}}$ from the suitable model. Accordingly, pseudo-second- order is the most suitable model to represent the adsorption of TC onto MIL-125/MIL-53/CNT@Alg composite microbeads (Table 2). It is apparent from the computed Elovich coefficients that $\alpha$ values are greater than $\beta$ values, indicating that the rate of adsorption is higher than desorption ${ }^{20}$.
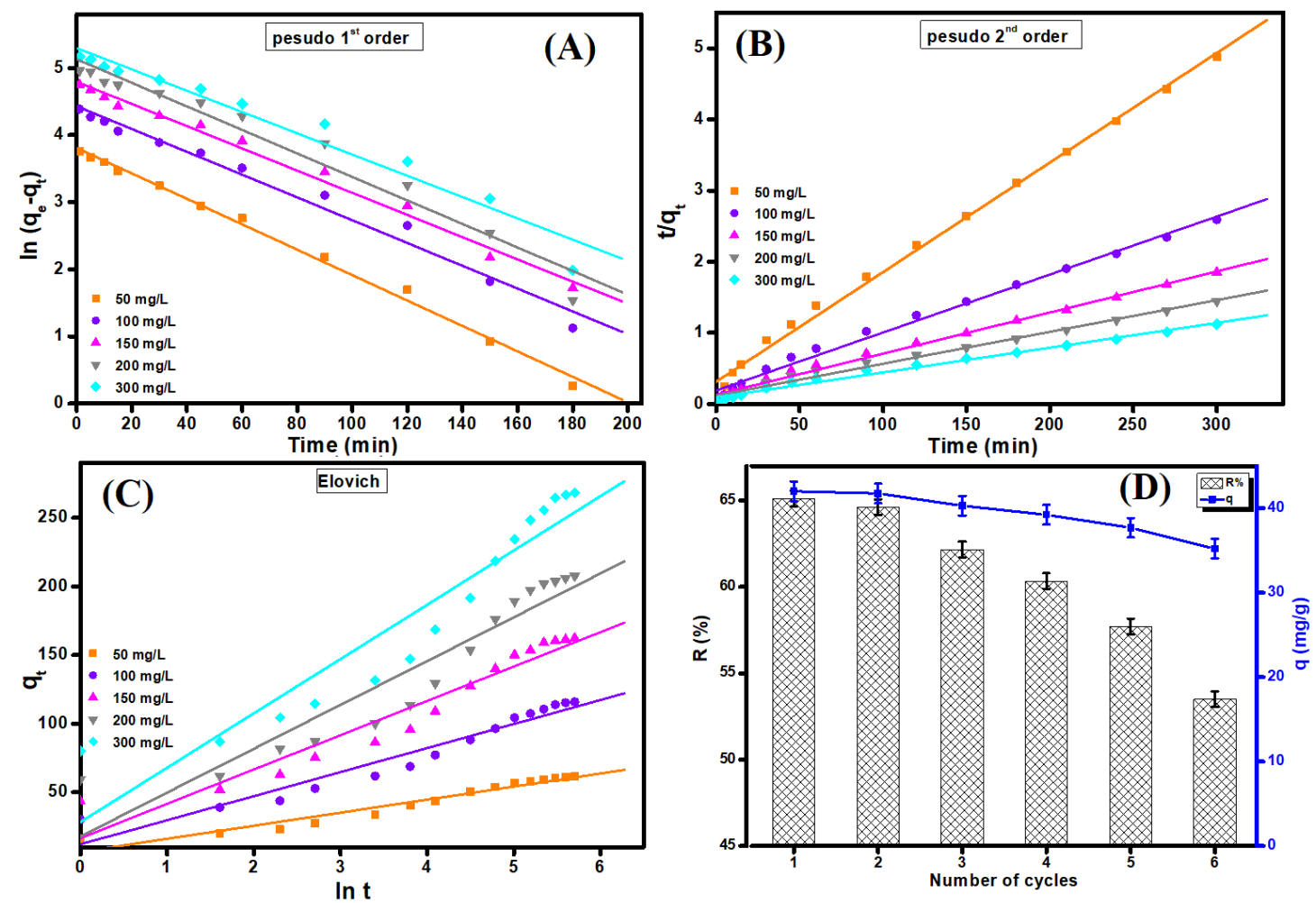
Figure 10. (A) Pseudo-first-order, (B) Pseudo-second-order and (C) Elovich kinetic models for adsorption of TC onto MIL-125/MIL-53/CNT@Alg composite microbeads. (D) Regeneration and reusability of MIL-125/MIL-53/CNT@Alg composite microbeads.

Table 2. Adsorption kinetic model parameters of the adsorption of TC onto MIL125/MIL-binary MOF/CNT@Alg composite microbeads

\begin{tabular}{lccccc}
\hline \multirow{2}{*}{ Kinetic models and parameters } & \multicolumn{5}{c}{ Concentration (mg/L) } \\
\cline { 2 - 6 } & 50 & 100 & 150 & 200 & 300 \\
\hline $\mathrm{q}_{\mathrm{e}, \text { exp }}(\mathrm{mg} / \mathrm{g})$ & 61.52 & 115.95 & 162.31 & 207.65 & 268.10 \\
$\underline{\text { Pseudo-first- order }}$ & & & & & \\
$\mathrm{q}_{\mathrm{e}, \mathrm{cal}}(\mathrm{mg} / \mathrm{g})$ & 45.07 & 48.01 & 120.83 & 168.85 & 199.60 \\
$\mathrm{k}_{1}\left(\mathrm{~min}^{-1}\right)$ & 0.018 & 0.017 & 0.016 & 0.018 & 0.015 \\
$\mathrm{R}^{2}$ & 0.995 & 0.981 & 0.989 & 0.961 & 0.958
\end{tabular}

\section{$\underline{\text { Pseudo-second-order }}$}

$\begin{array}{llllll}\mathrm{q}_{\mathrm{e}, \text { cal }}(\mathrm{mg} / \mathrm{g}) & 64.94 & 123.46 & 172.41 & 222.22 & 285.71 \\ \mathrm{k}_{2}\left(\mathrm{~g} \cdot \mathrm{mg}^{-1} \cdot \mathrm{min}^{-1}\right) & 0.007 & 0.004 & 0.003 & 0.002 & 0.001 \\ \mathrm{R}^{2} & 0.996 & 0.992 & 0.993 & 0.988 & 0.986\end{array}$

\section{$\underline{\text { Elovich }}$}

$\begin{array}{llllll}\alpha(\mathrm{mg} / \mathrm{g} \min ) & 20.239 & 32.980 & 43.730 & 65.319 & 80.940 \\ \beta(\mathrm{g} / \mathrm{mg}) & 0.101 & 0.059 & 0.040 & 0.031 & 0.025 \\ \mathrm{R}^{2} & 0.941 & 0.935 & 0.931 & 0.894 & 0.892\end{array}$

\subsection{Thermodynamic study}

As a matter of fact, the change in the process temperature directly affects the nature and the mechanism of adsorption. For deducing the effect of change the temperature from $298-328 \mathrm{~K}$ on the adsorption of TC onto MIL-125/MIL- 
53/CNT@Alg composite microbeads, equations (11-13) were utilized for calculating the thermodynamics parameter; change in free energy $\left(\Delta \mathrm{G}^{0}\right)$, change in enthalpy $\left(\Delta \mathrm{H}^{\circ}\right)$ and change in entropy $\left(\Delta \mathrm{S}^{\mathrm{o}}\right)$. The negative values of $\Delta \mathrm{G}^{\mathrm{o}}$ (Table 3) prove the spontaneity of this adsorption process.

$$
\begin{gathered}
\ln \mathrm{K}_{\mathrm{e}}=\frac{\Delta \mathrm{S}^{\mathrm{o}}}{\mathrm{R}}-\frac{\Delta \mathrm{H}^{\mathrm{o}}}{\mathrm{RT}} \\
\mathrm{K}_{\mathrm{e}}=\frac{\mathrm{C}_{\mathrm{Ae}}}{\mathrm{C}_{\mathrm{e}}} \\
\Delta \mathrm{G}^{\mathrm{O}}=\Delta \mathrm{H}^{\mathrm{O}}-\mathrm{T} \Delta \mathrm{S}^{\mathrm{o}}
\end{gathered}
$$

Where, $\mathrm{K}_{\mathrm{e}}$ is the thermodynamic equilibrium constant. $\mathrm{C}_{\mathrm{Ae}}$ is the TC concentration onto the surface of MIL-125/MIL-53/CNT@Alg composite microbeads, while $\mathrm{C}_{\mathrm{e}}$ is the concentration of $\mathrm{TC}$ in solution at equilibrium. $\mathrm{T}$ is the adsorption temperature and $\mathrm{R}$ is gas constant.

Figure S1 represents Van't Hoff Plot that elucidates $\Delta \mathrm{S}^{\mathrm{o}}$ and $\Delta \mathrm{H}^{\mathrm{o}}$ from the intercept and slope, respectively. The positive value of $\Delta \mathrm{S}^{\circ}$ and $\Delta \mathrm{H}^{\circ}$ indicates that the adsorption of TC onto the surface of MIL-125/MIL-53/CNT@Alg composite microbeads randomness and endothermic, respectively.

Table 3. Thermodynamic parameters of the adsorption of TC onto MIL-125/MILbinary MOF/CNT@Alg composite microbeads

\begin{tabular}{cccccc}
\hline & \multicolumn{1}{c}{$\mathbf{G}^{\circ}(\mathbf{k J} / \mathbf{m o l})$} & & $\Delta \mathbf{H}^{\circ}(\mathbf{k J} / \mathbf{m o l})$ & $\Delta \mathbf{S}^{\circ}(\mathbf{J} / \mathbf{m o l ~ K})$ \\
\hline $298 \mathrm{~K}$ & $308 \mathrm{~K}$ & $318 \mathrm{~K}$ & $328 \mathrm{~K}$ & & \\
\hline-22.77 & -23.53 & -24.29 & -25.06 & & 76.46 \\
\hline
\end{tabular}




\subsection{Regeneration study}

To assert the viability of our study, the recyclability of the fabricated MIL125/MIL-53/CNT@Alg composite microbeads was examined for six consecutive adsorption/desorption cycles. Figure 10D depicts an inconsiderable decrease in the removal (\%) and the adsorption capacity from $65.10 \%$ and $42.02 \mathrm{mg} / \mathrm{g}$ to $53.50 \%$ and $35.22 \mathrm{mg} / \mathrm{g}$, respectively, confirming the good recyclability of MIL-125/MIL53/CNT@Alg composite microbeads that renders us recommend our novel composite microbeads as a promising candidate for the removal of TC from an aqueous solution.

\subsection{Comparison study}

To sum, MIL-125/MIL-53/CNT@Alg composite microbeads possess a superb adsorption capacity toward TC compared with other MOFs-, carbon materials- or alginate beads-based adsorbents (Table 4). This finding suggests that the fabricated composite beads may be utilized in actual wastewater treatment taking into consideration the advantage of their easy separation and remarkable renewability.

Table 4. Comparison between the adsorption capacity of MIL-125/MIL-53binary MOF/CNT@Alg composite microbeads and other adsorbent towards the adsorption of TC.

\begin{tabular}{ccc}
\hline Adsorbent & qe $(\mathbf{m g} / \mathbf{g})$ & Reference \\
\hline CuCo/MIL-101 & 54.00 & 52 \\
BM-BC composite & 84.54 & 53 \\
UiO-66-(COOH) $/$ GO composite & 164.91 & 54 \\
MSABC composite & 98.33 & 55 \\
NiCoFe-MOF-74 composite & 102.94 & 56 \\
Alg-Cu beads & 53.26 & 57
\end{tabular}




$\begin{array}{ccc}\text { UiO-66-(OH) } 2 \text { / GO composite } & 37.96 & 58 \\ \text { MWCNT/MIL-53(Fe) composite } & 180.68 & 49 \\ \text { Co-SCGBC composite } & 370.37 & 59 \\ \text { ZIF-8 } & 277.80 & 60 \\ \text { UiO-66 } & 16.70 & 61 \\ \text { MIL-125/MIL-53binary } & 294.12 & \text { This study } \\ \text { MOF/CNT@ Alg beads } & & \end{array}$

\section{Conclusion}

All in all, this study presented the fabrication of MIL-125/MIL-53/CNT@Alg composite microbeads for removing of tetracycline drug residue from aqueous solutions. The formulated adsorbent composite was proved its chemical structure, thermal stability and surface morphology, while batch adsorption experiments were conducted to evaluate its aptitude for adsorption of TC under several optimization conditions. The results clarified that incorporation of $\mathrm{CNC}$ into the composite matrix played a significant role in the adsorption process, since the removal (\%) of TC was increased with increasing $\mathrm{CNC}$ quantity up to $15 \mathrm{w} \%$. A sequence of adsorption isotherm models and kinetic studies led us to conclude that the adsorption of TC onto MIL-125/MIL-53/CNT@Alg composite microbeads process was fitted to Freundlich and Langmuir isotherm model with a maximum adsorption capacity of $294.12 \mathrm{mg} / \mathrm{g}$ at $25{ }^{\circ} \mathrm{C}$, and followed the pseudo-second-order kinetic model, spontaneous. The results of thermodynamic studies clarified that the adsorption process could be described as spontaneous, endothermic and randomness process. Reusability studies confirmed that the developed adsorbent exhibited a superior recycling capability even after sex repeated cycles with good performance for adsorption of TC. Thus, the fabricated adsorbent composite has some operational benefits such as easy separation, decent 
adsorption performance and better reusability, suggesting its applicability for removing TC residue from aquatic mediums.

\section{References}

1 El-Subruiti, G., Eltaweil, A. \& Sallam, S. Synthesis of active MFe2O4/ $\mathrm{Y}-\mathrm{Fe} 2 \mathrm{O} 3$ nanocomposites (metal= $\mathrm{Ni}$ or $\mathrm{Co}$ ) for reduction of nitro-containing pollutants and methyl orange degradation. Nano 14, 1950125 (2019).

2 Sodhi, M. \& Etminan, M. Therapeutic Potential for Tetracyclines in the Treatment of COVID-19. Pharmacotherapy: The Journal of Human Pharmacology and Drug Therapy 40, 487-488 (2020).

3 Mosquera-Sulbaran, J. A. \& Hernández-Fonseca, H. Tetracycline and viruses: a possible treatment for COVID-19? Archives of virology, 1-7 (2020).

4 Thomson, J. A. RE: Transparency in the selection of therapeutic treatments: Where are the clinical trials of the tetracycline family (doxycycline) for SARS-CoV-2/COVID19? (2021).

5 Alatalo, S.-M. et al. Mechanistic insight into efficient removal of tetracycline from water by Fe/graphene. Chemical Engineering Journal 373, 821-830 (2019).

$6 \mathrm{Kim}, \mathrm{J}$. E. et al. Adsorptive removal of tetracycline from aqueous solution by maple leaf-derived biochar. Bioresource Technology, 123092 (2020).

7 Yi, X., Zhu, J., Yan, Y., Cheng, H. \& Xu, W. Removal of Tetracycline Hydrochloride $(\mathrm{TCH})$ in Simulated Wastewater by Zero-Valent Iron with Ultrasonic Irradiation (USZIV). Polish Journal of Environmental Studies 30, 903-916 (2020).

8 Shi, W. et al. Tetracycline removal from aqueous solution by visible-light-driven photocatalytic degradation with low cost red mud wastes. Chemical Engineering Journal 382, 122876 (2020).

9 Zhi, D. et al. Development of ozonation and reactive electrochemical membrane coupled process: Enhanced tetracycline mineralization and toxicity reduction. Chemical Engineering Journal 383, 123149 (2020).

$10 \mathrm{Li}, \mathrm{X}$. et al. Heterogeneous Fenton-like degradation of tetracyclines using porous magnetic chitosan microspheres as an efficient catalyst compared with two preparation methods. Chemical Engineering Journal 379, 122324 (2020).

11 Liu, Q. et al. Polyaniline as interface layers promoting the in-situ growth of zeolite imidazole skeleton on regenerated cellulose aerogel for efficient removal of tetracycline. Journal of colloid and interface science 579, 119-127 (2020).

12 Rizzi, V. et al. Removal of tetracycline from polluted water by chitosan-olive pomace adsorbing films. Science of The Total Environment 693, 133620 (2019).

13 Kong, Y., Zhuang, Y., Han, K. \& Shi, B. Enhanced tetracycline adsorption using alginate-graphene-ZIF67 aerogel. Colloids and Surfaces A: Physicochemical and Engineering Aspects 588, 124360 (2020).

14 Eltaweil, A. S., Elshishini, H. M., Ghatass, Z. F. \& Elsubruiti, G. M. Ultra-high adsorption capacity and selective removal of Congo red over aminated graphene oxide modified Mn-doped UiO-66 MOF. Powder Technology 379, 407-416 (2021). Jamshidifard, S. et al. Incorporation of UiO-66-NH2 MOF into the PAN/chitosan nanofibers for adsorption and membrane filtration of $\mathrm{Pb}$ (II), $\mathrm{Cd}$ (II) and $\mathrm{Cr}(\mathrm{VI})$ ions from aqueous solutions. Journal of hazardous materials 368, 10-20 (2019). Yang, Z.-h. et al. Mn-doped zirconium metal-organic framework as an effective adsorbent for removal of tetracycline and $\mathrm{Cr}(\mathrm{VI})$ from aqueous solution. Microporous and Mesoporous Materials 277, 277-285 (2019). 

aqueous solution using a metal-organic framework (MOF) MIL-101 (Fe): isotherms, kinetics, and thermodynamic studies. DESALINATION AND WATER TREATMENT 189, 395-407 (2020).

18 Yu, J. et al. Functionalized MIL-53 (Fe) as efficient adsorbents for removal of tetracycline antibiotics from aqueous solution. Microporous and Mesoporous Materials 290, 109642 (2019).

19 Fatima, R., Park, S. \& Kim, J.-O. Effect of molar ration of Ti/Ligand on the synthesis of MIL-125 (Ti) and its adsorption and photocatalytic properties. Journal of Industrial and Engineering Chemistry 90, 166-177 (2020).

20 Omer, A. M., Abd El-Monaem, E. M., Abd El-Latif, M. M., El-Subruiti, G. M. \& Eltaweil, A. S. Facile fabrication of novel magnetic ZIF-67 MOF@ aminated chitosan composite beads for the adsorptive removal of $\mathrm{Cr}(\mathrm{VI})$ from aqueous solutions. Carbohydrate Polymers 265, 118084 (2021).

21 Eldin, M. M. et al. Novel smart pH sensitive chitosan grafted alginate hydrogel microcapsules for oral protein delivery: II. Evaluation of the swelling behavior. International Journal of Pharmacy and Pharmaceutical Sciences 7, 331-337 (2015).

22 Gao, X., Li, M., Zhao, Y. \& Zhang, Y. Mechanistic study of selective adsorption of $\mathrm{Hg} 2+$ ion by porous alginate beads. Chemical Engineering Journal 378, 122096 (2019).

23 Aziz, F. et al. Composites with alginate beads: A novel design of nano-adsorbents impregnation for large-scale continuous flow wastewater treatment pilots. Saudi Journal of Biological Sciences 27, 2499-2508 (2020).

24 Kausar, A. et al. Biocomposite of sodium-alginate with acidified clay for wastewater treatment: Kinetic, equilibrium and thermodynamic studies. International journal of biological macromolecules 161, 1272-1285 (2020).

25 Tamer, T. et al. Formation of zinc oxide nanoparticles using alginate as a template for purification of wastewater. Environmental nanotechnology, monitoring \& management 10, 112-121 (2018).

26 Omer, A. M., Ahmed, M. S., El-Subruiti, G. M., Khalifa, R. E. \& Eltaweil, A. S. pHSensitive Alginate/Carboxymethyl Chitosan/Aminated Chitosan Microcapsules for Efficient Encapsulation and Delivery of Diclofenac Sodium. Pharmaceutics 13, 338 (2021).

27 Iqbal, J. et al. Synergistic effects of activated carbon and nano-zerovalent copper on the performance of hydroxyapatite-alginate beads for the removal of As3+from aqueous solution. Journal of Cleaner Production 235, 875-886 (2019).

28 Wang, B. et al. Alginate-based composites for environmental applications: a critical review. Critical Reviews in Environmental Science and Technology 49, 318-356 (2019).

29 Yang, Y., Narayanan Nair, A. K. \& Sun, S. Adsorption and diffusion of carbon dioxide, methane, and their mixture in carbon nanotubes in the presence of water. The Journal of Physical Chemistry C 124, 16478-16487 (2020).

30 Hayati, B. et al. Heavy metal adsorption using PAMAM/CNT nanocomposite from aqueous solution in batch and continuous fixed bed systems. Chemical Engineering Journal 346, 258-270 (2018).

31 Yang, Z. et al. Preparation of BiVO4/MIL-125 (Ti) composite with enhanced visiblelight photocatalytic activity for dye degradation. Applied Organometallic Chemistry 32, e4285 (2018).

32 Farbod, M., Tadavani, S. K. \& Kiasat, A. Surface oxidation and effect of electric field on dispersion and colloids stability of multiwalled carbon nanotubes. Colloids and Surfaces A: Physicochemical and Engineering Aspects 384, 685-690 (2011). 
33 McNamara, N. D., Neumann, G. T., Masko, E. T., Urban, J. A. \& Hicks, J. C. Catalytic performance and stability of (V) MIL-47 and (Ti) MIL-125 in the oxidative desulfurization of heterocyclic aromatic sulfur compounds. Journal of catalysis 305, 217-226 (2013).

34 Eltaweil, A. S., Abd El-Monaem, E. M., El-Subruiti, G. M., Abd El-Latif, M. M. \& Omer, A. M. Fabrication of UiO-66/MIL-101 (Fe) binary MOF/carboxylated-GO composite for adsorptive removal of methylene blue dye from aqueous solutions. RSC Advances 10, 19008-19019 (2020).

35 Eltaweil, A. S., El-Tawil, A. M., Abd El-Monaem, E. M. \& El-Subruiti, G. M. Zero valent iron nanoparticle-loaded nanobentonite intercalated carboxymethyl chitosan for efficient removal of both anionic and cationic dyes. ACS omega 6, 6348-6360 (2021). Ghann, W. et al. Terahertz Reflectometry Imaging of Carbon Nanomaterials for Biological Application. Journal of nanomedicine \& nanotechnology 10 (2019).

37 El-Monaem, E. M. A., El-Latif, M. M. A., Eltaweil, A. S. \& El-Subruiti, G. M. Cobalt nanoparticles supported on reduced amine-functionalized graphene oxide for catalytic reduction of nitroanilines and organic dyes. Nano 16, 2150039 (2021). Bhagyaraj, S. \& Krupa, I. Alginate-mediated synthesis of hetero-shaped silver nanoparticles and their hydrogen peroxide sensing ability. Molecules 25, 435 (2020). El Bestawy, E., El-Shatby, B. F. \& Eltaweil, A. S. Integration between bacterial consortium and magnetite ( $\mathrm{Fe} 3 \mathrm{O} 4$ ) nanoparticles for the treatment of oily industrial wastewater. World Journal of Microbiology and Biotechnology 36, 1-16 (2020).

40 Lopes, S., Bueno, L., AGUIAR JÚNIOR, F. D. \& Finkler, C. Preparation and characterization of alginate and gelatin microcapsules containing Lactobacillus rhamnosus. Anais da academia brasileira de ciências 89, 1601-1613 (2017).

41 Xiao, S. et al. Layer-by-layer assembly of polyelectrolyte multilayer onto PET fabric for highly tunable dyeing with water soluble dyestuffs. Polymers 9, 735 (2017).

42 Ranganathan, K. et al. Study of photoelectrochemical water splitting using composite films based on $\mathrm{TiO} 2$ nanoparticles and nitrogen or boron doped hollow carbon spheres as photoanodes. Journal of Molecular Catalysis A: Chemical 422, 165-174 (2016).

43 Eltouny, N. \& Ariya, P. A. Competing reactions of selected atmospheric gases on Fe 3 O 4 nanoparticles surfaces. Physical Chemistry Chemical Physics 16, 23056-23066 (2014).

44 Sadri, R. et al. A bio-based, facile approach for the preparation of covalently functionalized carbon nanotubes aqueous suspensions and their potential as heat transfer fluids. Journal of colloid and interface science 504, 115-123 (2017). Srivastava, M. et al. Zn x Fe 3- x $04(0.01 \leq x \leq 0.8)$ nanoparticles for controlled magnetic hyperthermia application. New Journal of Chemistry 42, 7144-7153 (2018). Bharti, B., Kumar, S., Lee, H.-N. \& Kumar, R. Formation of oxygen vacancies and Ti 3+ state in TiO 2 thin film and enhanced optical properties by air plasma treatment. Scientific reports 6, 1-12 (2016).

47 Gao, Y. et al. Adsorption and removal of tetracycline antibiotics from aqueous solution by graphene oxide. Journal of colloid and interface science 368, 540-546 (2012).

48 Zhang, L. et al. Studies on the removal of tetracycline by multi-walled carbon nanotubes. Chemical Engineering Journal 178, 26-33 (2011).

49 Xiong, W. et al. Adsorption of tetracycline antibiotics from aqueous solutions on nanocomposite multi-walled carbon nanotube functionalized MIL-53 (Fe) as new adsorbent. Science of the Total Environment 627, 235-244 (2018). 

Fabrication of novel iminodiacetic acid-functionalized carboxymethyl cellulose microbeads for efficient removal of cationic crystal violet dye from aqueous solutions. International journal of biological macromolecules 148, 1072-1083 (2020). El-Sayed, E., Tamer, T., Omer, A. \& Mohy Eldin, M. Development of novel chitosan schiff base derivatives for cationic dye removal: methyl orange model. Desalination and Water Treatment 57, 22632-22645 (2016).

52 Jin, J. et al. Cu and Co nanoparticles co-doped MIL-101 as a novel adsorbent for efficient removal of tetracycline from aqueous solutions. Science of The Total Environment 650, 408-418 (2019).

53 Xiang, W. et al. Adsorption of tetracycline hydrochloride onto ball-milled biochar: Governing factors and mechanisms. Chemosphere 255, 127057 (2020).

54 Wang, K., Wu, J., Zhu, M., Zheng, Y.-Z. \& Tao, X. Highly effective pH-universal removal of tetracycline hydrochloride antibiotics by UiO-66-(COOH) 2/GO metalorganic framework composites. Journal of Solid State Chemistry 284, 121200 (2020).

55 Zhang, X. et al. Enhanced adsorption of tetracycline by an iron and manganese oxides loaded biochar: Kinetics, mechanism and column adsorption. Bioresource Technology 320, 124264 (2021).

56 Xiao, R. et al. Fabrication of magnetic trimetallic metal-organic frameworks for the rapid removal of tetracycline from water. Analyst 145, 2398-2404 (2020).

57 Zhang, X. et al. Study on adsorption of tetracycline by Cu-immobilized alginate adsorbent from water environment. International journal of biological macromolecules 124, 418-428 (2019).

58 Sun, Y. et al. Adsorptive removal of dye and antibiotic from water with functionalized zirconium-based metal organic framework and graphene oxide composite nanomaterial Uio-66-(OH) 2/GO. Applied Surface Science 525, 146614 (2020).

59 Nguyen, V.-T. et al. Cobalt-impregnated biochar (Co-SCG) for heterogeneous activation of peroxymonosulfate for removal of tetracycline in water. Bioresource technology 292, 121954 (2019).

60 Li, N., Zhou, L., Jin, X., Owens, G. \& Chen, Z. Simultaneous removal of tetracycline and oxytetracycline antibiotics from wastewater using a ZIF-8 metal organicframework. Journal of hazardous materials 366, 563-572 (2019).

61 Chen, C. et al. Adsorption behaviors of organic micropollutants on zirconium metalorganic framework UiO-66: analysis of surface interactions. ACS applied materials \& interfaces 9, 41043-41054 (2017).

\section{Author contributions}

A.M.O. and A.S.E. proposed the research concept; E.M.A. conducted the experiments; E.M.A. and A.S.E. prepared figures; A.S.E., A.M.O. and E.M.A. analyzed, interpreted the data and wrote the manuscript; A.M.O., A.S.E., G.M.E. and

M.M.A. revised the manuscript.

Competing interests: The authors declare that they have no competing interests. 


\section{Supplementary Files}

This is a list of supplementary files associated with this preprint. Click to download.

- Supplementarymaterial.docx 